\title{
Readiness to Implement School-Based Social-Emotional Learning Interventions: Using Research on Factors Related to Implementation to Maximize Quality
}

\author{
Shannon B. Wanless ${ }^{1}$ - Celene E. Domitrovich ${ }^{2,3}$
}

Published online: 14 October 2015

(C) Society for Prevention Research 2015

In the past several years, interest in social and emotional learning (SEL) has grown significantly. What was once a specialized domain of educational research and practice is now a significant movement with greater numbers of practitioners, policy-makers, and researchers recognizing the importance of social and emotional competence for students' success in school and life (Durlak et al. 2015). SEL involves fostering social and emotional competencies in children through various strategies including direct instruction and studentcentered practices that create engaging learning environments nurturing students' development of analytical, communication, and collaboration skills (CASEL 2013; Jones and Bouffard 2012).

Social and emotional interventions have evolved out of different traditions including education, social work, child psychiatry, public health, psychology, and prevention (Catalano et al. 2004; Greenberg et al. 2001; Hahn et al. 2007; Wilson and Lipsey 2007). The evidence base for these programs has grown steadily since rigorous trials first established their positive impact on behavioral and academic outcomes; there are now several meta-analyses summarizing this body of research (Durlak et al. 2011; Sklad et al. 2012). As non-academic competencies are increasingly incorporated into learning standards at the preschool and elementary levels, and federal and state funding agencies require the use of evidence-based interventions (EBIs) as part of their

Shannon B. Wanless

swanless@pitt.edu

1 University of Pittsburgh, Pittsburgh, PA, USA

2 Collaborative for Academic, Social, and Emotional Learning (CASEL), Chicago, IL, USA

3 Pennsylvania State University, University Park, PA, USA accountability requirements, early childhood education programs and schools are implementing SEL interventions more frequently than in the past. Interest in SEL interventions has also increased internationally (for examples, see Kam and Yick 2013; Yoshikawa et al. 2015). Using evidence-based SEL interventions, however, is not enough to ensure positive outcomes. The success of an intervention on children's social emotional competence depends on how it is implemented (e.g., Durlak and Dupre 2008; Durlak et al. 2011; Elias 2006; Greenberg et al. 2003, 2005). Recent research has increased understanding of this process by identifying a number of factors that enhance and undermine implementation success.

The primary goal of this special issue is to feature research examining factors that were assessed prior to the delivery of an SEL intervention, and their relations to implementation. Specifically, by highlighting the state of schools and teachers before they begin implementing a SEL intervention, it may be possible to understand which schools are more or less likely to implement successfully, and see opportunities for increasing that likelihood. Given that the factors researched in this special issue were evident prior to intervention delivery, we believe it is appropriate to conceptualize them as aspects of readiness to implement EBIs. Included in this special issue introduction is a definition of readiness, an overview of how the findings from the papers included in this special issue have implications for understanding this concept, and examples of existing initiatives that might be used to improve readiness to implement EBIs.

Influenced by the increase in type II translational research, many funding agencies that endorse the use of evidence-based interventions (EBIs), such as the U.S. Department of Education's Institute for Educational Sciences, now require researchers to include measures in research proposals to monitor intervention implementation. Intervention developers are 
also attending to implementation issues by developing materials and training methods with implementation outcomes in mind (Sandler et al. 2005). Finally, the Society for Prevention Research MAPS committee has elaborated a model for future research endeavors in this domain (Spoth et al. 2013).

There are several phases that schools must negotiate to establish the effective and sustained use of an EBI (Greenberg et al. 2005). The first, referred to as the adoption phase, is the process of selecting an intervention and preparing for its use. The second, referred to as the implementation or delivery phase, is the period in which the intervention is first conducted. This is followed by a post-delivery or sustainability phase in which an intervention is maintained over time. Several conceptual models of implementation take an ecological or systems approach to organizing the factors at multiple levels within a school that influence this process across all of these phases (Domitrovich et al. 2008; Durlak and Dupre 2008). These include (1) individual factors such as the knowledge, skills, and attitudes of the individuals delivering the intervention (e.g., teachers); (2) classroom factors such as the composition of the students, or the structure of daily schedule; and (3) building level factors such as characteristics of the leadership or the school climate.

The multi-level factors that influence implementation of school-based interventions may not all be equally relevant at each phase (Domitrovich et al. 2008). Many implementation research studies focus on identifying concurrent factors that explain variation in fidelity during the implementation phase as opposed to examining factors that are in place before an intervention is selected or that emerge early on when an intervention starts. The premise underlying this special issue is that the factors assessed prior to when an intervention starts, that emerge as significantly related to implementation outcomes, are all potential indicators of readiness. Although some factors associated with implementation may be unique to a certain type of intervention, many are likely to generalize, especially when interventions are conducted in the same setting, with a similar population, or are focused on similar content.

\section{Implementation Readiness}

The definition of implementation readiness guiding this special issue is the capacity to implement an EBI effectively. We suggest that readiness is a characteristic of individuals and organizations that may be evident during the adoption phase, before intervention use begins, and carry over into the early part of the implementation phase, when intervention delivery has only recently begun. Specifically, factors that are present during the adoption phase and that positively predict fidelity during the implementation phase may be thought of as indicators of readiness. Implementation theories and frameworks suggest that considering readiness, or capacity, before a school begins preparing to implement a new intervention is an essential initial step in the implementation process. For example, in the Quality Implementation Framework, the first 10 of 14 steps are focused on the needs of the school before implementation begins (Meyers et al. 2012). These include assessing the fit between the context's readiness and the intervention and doing any capacity building needed.

As alluded to in the Quality Implementation Framework (Meyers et al. 2012), a balance is needed between general readiness to implement and intervention-specific readiness. Although individuals and organizations may have a certain readiness to take on any new intervention, readiness likely varies depending on the intervention chosen. It may be useful to think of an individual and an organization as having a general range of readiness, and then within that, a specific readiness for a particular intervention given its complexity and fit with the existing beliefs, practices, and culture of the context.

One recently developed way of conceptualizing readiness takes into account this balance between general and intervention-specific readiness using the formula, $R=M C^{2}$ $($ Readiness $=$ Motivation $\times$ General Capacity $\times$ Intervention Specific Capacity; Scaccia et al. 2015). In this formula, the authors suggest that being motivated to use a new intervention is important but is not enough. Instead, there are general capacities (organizational culture, climate, receptiveness to innovation, willingness to allocate resources to new interventions, leadership, day-to-day functionality, and staff skills and expertise) and intervention-specific capacities (e.g., intervention-specific knowledge and skills, a champion for the new intervention, specific implementation supports, and strong relationships among providers, coaches, and other organizations that will support the implementation) that must also be in place. Although it is not clear whether all of these components should be weighted evenly for different interventions and contexts, it is clear that readiness is a multidimensional construct.

As the conceptualization of readiness continues to evolve, it is important to remember the practical challenges to incorporating the concept into real-world research and intervention implementation. Too often, research or professional development grants are awarded and EBI training begins right away, without any consideration of the people delivering the program or the setting in which it is implemented. Although many organizations may appear to have a high level of readiness because they sought out the EBI and the funding for it (motivation), it may be important to consider other indicators of readiness that influence the implementation process. Teachers report that even when their principals volunteer their school for training on a new EBI, motivation is not always evident in principal actions and priorities (Wanless et al. 2013). In fact, low readiness may be surprisingly prevalent. In a study of over 200 preschool teachers, coaches reported 
that $34 \%$ of teachers were not ready to change their teaching practices (Peterson 2012). Assessing the state of a constellation of factors that make teachers and schools more or less ready, and tailoring implementation supports for those teachers, may be one way to increase the implementation quality and sustainability of SEL interventions (Domitrovich et al. 2008; Wanless et al. 2015a, b, c). Research is needed to identify the critical aspects of school and teacher capacity for change that are measureable and have predictive utility for later implementation quality. We believe the studies included in this special issue provide an important first step in this effort.

\section{Overview of Special Issue}

This special issue, Readiness to Implement Social-Emotional Learning Interventions, seeks to inform this aspect of implementation science using empirical studies of school-based SEL interventions that identify baseline predictors of implementation fidelity of SEL programs conducted in preschool and elementary school settings. The studies examine seven social-emotional learning (SEL) interventions; two that are conducted in preschool settings and five that are conducted in elementary settings. All of the interventions have prior research that documents the effectiveness of their approach. Across all of the papers, there is a focus on identifying theoretically meaningful constructs during the adoption phase (or at the beginning of the implementation phase, when necessary) and exploring how they relate to future implementation quality.

The articles assess a wide variety of factors within and between educational levels (i.e., school, classroom, and student) as is suggested by several frameworks for understanding implementation in educational settings (Domitrovich et al. 2008; Paulsell et al. 2013). School level factors in this special issue range from school size and type, suspension rate and behavioral disruptions, support among teachers and climate, and school openness to innovation and SEL-related interventions. The classroom level is the least often addressed, although factors such as characteristics of the student population (race and poverty level) were included. The classroom level also includes teacher factors and in these studies those included teacher demographic characteristics and background, education level, beliefs, personality, emotional functioning (i.e., anxiety and stress), and their perceptions of the school and EBI effectiveness. It is likely that researchers more often focus on teachers because teachers are the direct implementers of most SEL EBIs, and thus there is much attention paid to them throughout the training and implementation support process. Moreover, teachers often seem most accessible for data collection as they are already providing data on other aspects of the study, and are present at training sessions and for classroom observations.

It is interesting to note that the construct of stress has been conceptualized at different levels across different studies in this issue; that is, school level stress (Roberts et al. 2015) and teacher level stress (Domitrovich et al. 2015). The meaning of these constructs changes across levels, and in some cases, so does their statistical significance. Readiness researchers may need to consider the implications of conceptualizing aspects of readiness on certain levels, how that impacts the measures chosen to assess them, and their utility. The wide variation in the type of factors that were assessed in the studies included in this special issue underscores the early stage of this line of inquiry in which researchers are still exploring possible factors, and there is more variation than consistency in the measurement approaches taken.

Level of Specificity Existing implementation frameworks suggest that readiness may include some aspects of general readiness (readiness to implement any EBI) and some aspects that are specific to the EBI being considered (Dymnicki et al. 2014). An example of a general readiness capacity might be the organization's openness to change, and an example of a specific capacity might be the use of a particular technology (e.g., smart boards) that is part of the intervention. The majority of studies in this special issue focus on general readiness, although some include intervention specific readiness such as perceptions of the effectiveness of the intervention (Pas et al. 2015; Domitrovich et al. 2015; Lochman et al. 2015) or use of intervention practices before training occurred (Wanless et al. $2015 a, b, c)$. The more frequent focus on factors that reflect general readiness may be a function of the practical utility of this general construct for the field. From a school's or district's perspective, it may be useful to have a measure of general readiness because schools often implement more than one EBI at a time. A measure of general readiness may help them to determine how to approach the upcoming year's array of training sessions. Districts may also want to understand the general degree of readiness of individual schools so they may make informed choices about allocating resources for a number of EBIs. Like the balance of emphases in this special issue, it may be helpful for the field to continue to consider intervention-specific readiness, while not losing sight of the practical utility of a more general understanding of readiness.

In addition to clarifying the balance of measuring general and intervention-specific aspects of readiness, research is also needed to determine the most reliable and valid reporters to provide ratings on these constructs. Just as a study in this special issue (Williford et al. 2015) incorporated multiple sources of information to create a composite of fidelity of implementation, it may be useful to take a similar approach to assessing readiness once the relevant factors are identified. Research in this area has just begun and preliminary findings 
are mixed suggesting more work is needed. In some related research, ratings by educational leaders (elementary principals) do not show high predictive validity (Wanless et al. 2013), but in other research, ratings by leaders (preschool directors) show greater potential as readiness raters (Wanless et al. 2015a, b, c). Most articles here rely heavily on teacher report, but some incorporate other perspectives, such as Lochman et al.'s (2015) use of student report. Once it is clear what aspects of readiness to focus on, measurement development that examines the use of multiple perspectives will be needed.

Implementation Outcomes Previous research and the findings of the studies included in this special issue suggest that factors within and across educational levels are differentially predictive of implementation outcomes depending on what indicator is assessed. Although there is an abundance of research documenting the importance of fidelity (Durlak and Dupre 2008; Durlak et al. 2011; Elias 2006; Greenberg et al. 2003, 2005), there are a multitude of accepted conceptualizations of implementation. Some of these studies reflected the traditional conceptualization of fidelity of implementation (adherence, dosage, quality, participant responsiveness, and program differentiation) established by Dane and Schneider (1998). The articles featured in this issue assessed dosage, quality of intervention delivery, responsiveness, use of practices in the classroom versus supplemental schoolwide practice, and generalization. Although this special issue does not address which aspects of fidelity are most useful to assess, the differences across studies are important to note when synthesizing the findings of which readiness aspects have the greatest predictive utility. In other words, this variation in conceptualizations of fidelity serves as a reminder that as we search for key aspects of readiness, it is important to ask which aspects of readiness may predict specific aspects of implementation.

Some of the articles in this special issue conceptualize implementation more broadly than the traditional definition of fidelity, which is the use of intervention practices in the classroom, as intended. Examples include use of supplemental activities outside of the classroom (Malloy et al. 2015), use of practices outside of school (Roberts et al. 2015), and use of generalized practices (Williford et al. 2015). It is possible that having higher readiness will also lead to positive use of practices beyond the original intent of the training. For example, when there are scripted activities, it is possible that a high level of readiness would allow teachers to internalize the underlying principles and messages of the scripted activities, and let them surface in other contexts and at other times of the day. This generalized implementation, or relatedly, positive adaptations of the intervention practices, may have the potential to lead to even stronger SEL outcomes for children.
Mechanisms In order to develop implementation support systems that improve an individual or school's readiness, researchers need to examine the mechanisms through which various factors relate to implementation. Training is one of the most common activities designed to improve a number of implementer readiness factors including intervention buy-in and knowledge. One article in this special issue investigates the role of teacher engagement in training as an important mechanism (Wanless et al. 2015a, b, c). There are many other potential mechanisms to be examined in future research including relational trust and psychological safety (Bryk et al. 2010; Edmondson and Lei 2014). It is not clear yet whether certain aspects of readiness make teachers feel comfortable trusting their coworkers to support them as they change their practice. It may be that certain characteristics, such as self-efficacy or openness to innovation, could be considered indicators of readiness since these provide teachers with the emotional freedom to try a new practice without worrying about being labeled as incompetent if the practice does not go well the first time.

\section{Examples of Implementation Support Initiatives}

Although we are not aware of interventions that specifically aim to increase readiness to implement EBIs, we describe three initiatives that may potentially support readiness by targeting capacity building. The first attends to the broadest level of change: the systems level. Experts in the field of SEL suggest that the strongest benefit of school-based programs designed to promote students' intra- and interpersonal competence are achieved when programs are conducted in the context of a systemic district and schoolwide approach (Elias et al. 2015; Mart et al. 2015; Meyers et al. 2015; Oberle et al. 2016). According to CASEL, this includes the following core components and support features: (a) a shared vision for SEL that prioritizes the promotion of social, emotional, and academic learning for all students; (b) a process for identifying existing strengths and supports for SEL and building from those strengths; (c) central office and school infrastructures and resources that provide ongoing professional learning; (d) evidence-based programs that support social and emotional skill development in classrooms and through the school community; (f) the integration of SEL within all areas of school functioning (i.e., across multiple setting levels); and (g) a datadriven cycle of inquiry that is designed to improve SEL practice and student outcomes (Weissberg et al. 2015). In order to put these elements in place, CASEL has developed a planning and implementation support intervention for systemic schoolwide SEL (Meyers et al. 2015). The CASEL Guide to Schoolwide SEL is currently being tested in a 28 -school 
randomized clinical trial in Chicago (Domitrovich et al. 2015). All 28 schools are implementing the Promoting Alternative Thinking Strategies (PATHS) Curriculum in grades K-3. Half the schools will conduct the program following a standard training and support model and the other half will implement the program in the context of a schoolwide support model. This 2-year process of schoolwide support involves schools creating an SEL leadership team that meets monthly and the provision of ongoing support to the principal and the SEL team from an SEL coach. If successful, this "readiness-related" initiative will address many of the multilevel factors identified in the studies included in this special issue.

A second initiative that holds promise for promoting individual and organizational readiness takes a school level approach to capacity building. Leading Together (LT) is intervention that is designed to build the individual strengths of school leaders. It has just completed an initial study demonstrating its potential. The intervention begins with a 4-day summer retreat and continues for 2 years with additional retreat days and school coaching. During the retreats and coaching, participants learn reflective and mindfulness practices, build adult community, and grow intra- and interpersonally (Seigle et al. 2012). A 2-year study of LT in eight elementary schools found that schools that implemented LT fully had increased professional capacity, relational trust, and academic optimism (Rimm-Kaufman et al. 2014). Although it is yet to be determined if these factors are indicators of readiness, they are closely aligned with the conceptualizations in some of the articles in this special issue, and with previous research on schoolwide change (e.g., Bryk et al. 2010). This and other inservice teacher interventions may provide a way to increase readiness before schools embark on expensive interventions they may or may not be ready for.

Finally, another approach to building individual teacher capacity that has potential as a readiness intervention is preservice training. Teacher education programs provide a unique and largely untapped opportunity for increasing readiness to implement evidence-based interventions. While this approach does not address readiness at the organization level, it could increase teachers' readiness to implement interventions by increasing their knowledge of social-emotional development and skill at delivering interventions. As part of preliminary data collection for a year-long, mindfulnessbased course at the University of Pittsburgh (Attentional Teaching Practices; ATP), findings indicated that preservice teachers with greater trait mindfulness felt greater general capacity to begin teaching in high schools in the following year (Wanless et al. 2014). This finding combined with other ongoing research on preservice teacher education and mindfulness suggests that focusing on the teachers on social and emotional skills may offer another vehicle for increasing teacher readiness to implement in their future placements (Jennings 2014; Margolis et al. 2014).

\section{Concluding Remarks}

Research is needed to determine what specific aspects of readiness are most important, how individual or organizational aspects of readiness interact with one another, how much readiness can be effectively conceptualized as a general construct versus an intervention-specific construct, and how to measure and improve readiness. Despite these questions, it seems likely that readiness may include a constellation of indicators that may contribute to differing degrees, and may interact with one another (Wanless et al. 2015a, b, c). Knowing which factors predict a school's likelihood of high implementation before training or program delivery begins may give stakeholders a signal of what implementation challenges they may encounter, allowing them to take a more individualized approach to creating implementation support systems. This approach would also allow schools or districts to allocate resources for implementation supports more strategically in an effort to increase efficacy of the intervention in a cost-effective way. Across all of the papers in this special issue, one message is clear: Before amassing resources or assembling a team of stakeholders, it is important to ask, "Does this teacher, and this school, have the capacity to take on this intervention?"

\section{Compliance with Ethical Standards}

Conflict of Interest Dr. Wanless has no conflicts of interest with respect to authorship on the publication of this article. Dr. Domitrovich is an author on the PATHS Curriculum and has a royalty agreement with Channing-Bete, Inc. This has been reviewed and managed by Penn State's Individual Conflict of Interest Committee.

Human Participants and/or Animals There were no human or animal participants involved in this article.

Informed Consent Informed consent was not needed for this article.

\section{References}

Bryk, A. S., Sebring, P. B., Allensworth, E., Easton, J. Q., Luppescu, S. (2010). Organizing schools for improvement: Lessons from Chicago. University of Chicago Press.

Catalano, R. F., Berglund, M. L., Ryan, J. A. M., Lonczak, H. S., \& Hawkins, J. D. (2004). Positive youth development in the United States: Research findings on evaluations of positive youth development programs. The ANNALS of the American Academy of Political and Social Science, 591, 98-124. doi:10.1177/0002716203260102.

Collaborative for Academic, Social, and Emotional Learning. (2013). 2013 guide: Effective social and emotional learning programs: Preschool and elementary school edition. Chicago: Author.

Dane, A. V., \& Schneider, B. H. (1998). Program integrity in primary and early secondary prevention: Are implementation effects out of control? Clinical Psychology Review, 18, 23-4. doi:10.1016/S02727358(97)00043-3. 
Domitrovich, C. E., Bradshaw, C. P., Poduska, J. M., Hoagwood, K., Buckley, J. A., Olin, S., ..., Ialongo, N. S. (2008). Maximizing the implementation quality of evidence-based preventive interventions in schools: A conceptual framework. Advances in School Mental Health Promotion, 1, 6-28. doi: 10.1080/1754730X.2008.9715730.

Domitrovich, C. E., Pas, E. T., Bradshaw, C. P., Becker, K. D., Keperling, J. P., Embry, D. D., \& Ialongo, N. (2015). Individual and school organizational factors that influence implementation of the PAX Good Behavior Game intervention. Prevention Science. doi:10. 1007/s11121-015-0557-8.

Durlak, J. A., \& DuPre, E. P. (2008). Implementation matters: A review of research on the influence of implementation on program outcomes and the factors affecting implementation. American Journal of Community Psychology, 41, 327-350. doi:10.1007/s10464-0089165-0.

Durlak, J. A., Weissberg, R. P., Dymnicki, A. B., Taylor, R. D., \& Schellinger, K. B. (2011). The impact of enhancing students' social and emotional learning: A meta-analysis of school-based universal interventions. Child Development, 82, 405-432. doi:10.1111/j. 1467-8624.2010.01564.x.

Durlak, J. A., Domitrovich, C. E., Weissberg, R. P., \& Gullotta, T. P. (2015). Handbook of social and emotional learning: Research and practice. New York: Guilford.

Dymnicki, A., Wandersman, A., Osher, D., Grigorescu, V., Huang, L. (2014). Willing, able, ready: Basics and policy implications of readiness as a key component for implementation of evidence-based practices. (ASPE Issue Brief. Washington, DC: Office of the Assistant Secretary for Planning and Evaluation, Office of Human Services Policy). Washington, DC: U.S. Department of Health and Human Services.

Edmondson, A. C., \& Lei, Z. (2014). Psychological safety: The history, renaissance, and future of an interpersonal construct. Annual Review of Organizational Psychology and Organizational Behavior, 1, 2343. doi:10.1146/annurev-orgpsych-031413-091305.

Elias, M. J. (2006). The connection between academic and social-emotional learning. In M. J. Elias \& H. Arnold (Eds.), The educator's guide to emotional intelligence and academic achievement (pp. 4 14). Thousand Oaks: Corwin Press.

Elias, M. J., Leverett, L., Duffell, J. C., Humphrey, N., Stepney, C., \& Ferrito, J. (2015). Integrating SEL with related prevention and youth development approaches. In J. A. Durlak, C. E. Domitrovich, R. P. Weissberg, \& T. P. Gullotta (Eds.), Handbook for social and emotional learning: Research and practice (pp. 33-49). New York: Guilford.

Greenberg, M. T., Domitrovich, C., \& Bumbarger, B. (2001). The prevention of mental disorders in school-aged children: Current state of the field. Prevention \& Treatment, 4, 1-62.

Greenberg, M. T., Domitrovich, C. E., Craczyk, P. A., \& Zins, J. E. (2005). The study of implementation in school-based preventive interventions: Theory, research, and practice. Promotion of mental health and prevention of mental and behavior disorders (Vol. 3). Washington, DC: U.S. Department of Health and Human Services.

Greenberg, M. T., Weissberg, R. P., O’Brien, M. U., Zins, J. E., Fredericks, L., Resnik, H., \& Elias, M. J. (2003). Enhancing school-based prevention and youth development through coordinated social, emotional, and academic learning. American Psychologist, 58, 466-474.

Hahn, R., Fuqua-Whitley, D., Wethington, H., Lowy, J., Crosby, A., Fullilove, M., ... \& Task Force on Community Preventive Services. (2007). Effectiveness of universal school-based programs to prevent violent and aggressive behavior: A systematic review. American Journal of Preventive Medicine, 33, S114-S129.

Jennings, P. A. (2014). Early childhood teachers' well-being, mindfulness, and self-compassion in relation to classroom quality and attitudes towards challenging students. Mindfulness, 1-12. doi: 10. 1007/s12671-014-0312-4.
Jones, S. M., \& Bouffard, S. M. (2012). Social and emotional learning in schools: From programs to strategies. Social Policy Report, 26, 133.

Kam, C. M., \& Yick, Y. Y. (2013). Promoting social emotional learning among pre-schoolers in Chinese kindergartens: A feasibility study of preschool PATHS implementation in Hong Kong. Paper presented at the 4th European Network for Social and Emotional Competence (ENSEC) Conference, Zagreb. Abstract retrieved from http://hub. hku.hk/handle/10722/187083.

Lochman, J. E., Powell, N. P., Boxmeyer, C. L., Qu, L., Sallee, M., Wells, K. C., \& Windle, M. (2015). Counselor-level predictors of sustained use of an indicated preventive intervention for aggressive children. Prevention Science. doi:10.1007/s11121-014-0511-1.

Malloy, M., Acock, A., DuBois, D. L., Vuchinich, S., Silverthorn, N., Ji, P., \& Flay, B. R. (2015). Teachers' perceptions of school organizational climate as predictors of dosage and quality of implementation of a social-emotional and character development program. Prevention Science. doi:10.1007/s11121-014-0534-7.

Margolis, J., Hodge, A., \& Alexandrou, A. (2014). The teacher educator's role in promoting institutional versus individual teacher well-being. Journal of Education for Teaching: International Research and Pedagogy, 40, 391-408. doi:10.1080/02607476.2014.929382.

Mart, A. K., Weissberg, R. P., \& Kendziora, K. (2015). Systemic support for social and emotional learning in school districts. In J. A. Durlak, C. E. Domitrovich, R. P. Weissberg, \& T. P. Gullotta (Eds.), Handbook of social and emotional learning: Research and practice (pp. 482-499). New York: Guilford.

Meyers, D. C., Durlak, J. A., \& Wandersman, A. (2012). The quality implementation framework: A synthesis of critical steps in the implementation process. American Journal of Community Psychology, 50, 462-480. doi:10.1007/s10464-012-9522-x.

Meyers, D. C., Gil, L., Cross, R., Keister, S., Domitrovich, C. E., \& Weissberg, R. P. (2015). CASEL guide for schoolwide social and emotional learning. Chicago.

Oberle, E., Domitrovich, C. E., Meyers, D. C., \& Weissberg, R. P. (2016). Establishing systemic social and emotional learning approaches in schools: A framework for schoolwide implementation. Cambidge Journal of Education, (in press)

Pas, E. T., Waasdorp, T. E., \& Bradshaw, C. P. (2015). Examining contextual influences on classroom-based implementation of Positive Behavior Support strategies: Findings from a randomized controlled effectiveness trial. Prevention Science. doi:10.1007/s11121-0140492-0.

Paulsell, D., Austin, A. M. B., \& Lokteff, M. (2013). Measuring implementation of early childhood interventions at multiple system levels (OPRE Research Brief OPRE 2013-16). Washington, DC: Office of Planning, Research and Evaluation, Administration for Children and Families, U.S. Department of Health and Human Services.

Peterson, S. M. (2012). Understanding early educators' readiness to change. NHSA Dialog, 15, 95-112.

Rimm-Kaufman, S.E., Leis, M, \& Paxton, C. (2014). Innovating together to improve the adult community in schools: Results from a two-year study of the initial implementation of Leading Together. Retrieved from http://www.couragerenewal.org/PDFs/UVA LeadingTogether_July_11_2014_Final_Full_Report.pdf.

Roberts, A. M., LoCasale-Crouch, J., DeCoster, J., Hamre, B. K., Downer, J. T., Williford, A. P., \& Pianta, R. C. (2015). Individual and contextual factors associated with pre-kindergarten teachers' responsiveness to the MyTeachingPartner coaching intervention. Prevention Science. doi:10.1007/s11121-014-0533-8.

Sandler, I., Ostrom, A., Bitner, M. J., Ayers, T. S., Wolchik, S., \& SmithDaniels, V. (2005). Developing effective prevention services for the real world: A prevention service development model. American Journal of Community Psychology, 35, 127-142. doi:10.1007/ s10464-005-3389-z. 
Scaccia, J. P., Cook, B. S., Lamont, A., Wandersman, A., Castellow, J., Katz, J., \& Beidas, R. S. (2015). A practical implementation science heuristic for organizational readiness: $\mathrm{R}=\mathrm{MC}^{2}$. Journal of Community Psychology, 43, 484-501. doi:10.1002/jcop.21698.

Seigle, P., Wood, C., Sankowski, L., \& Ackerman, R. (2012). Leading together: Building adult community in schools. The Courage \& Renewal guidebook for Courage in Schools leadership programs. Seattle: Center for Courage \& Renewal.

Sklad, M., Diekstra, R., Ritter, M. D., Ben, J., \& Gravesteijn, C. (2012). Effectiveness of schoolbased universal social, emotional, and behavioral programs: Do they enhance students' development in the area of skill, behavior, and adjustment? Psychology in the Schools, 49, 892-909.

Spoth, R., Rohrbach, L. A., Greenberg, M. T. Robertson, E., Leaf, P., Brown, C. H., ... Hawkins, J.D. (2013). Addressing challenges for the next generation of type 2 translation research: The translation science to population impact framework. Prevention Science 14, 319-351. doi: 10.1007/s11121-012-0362-6.

Wanless, S. B., Patton, C. S., Rimm-Kaufman, S. E., \& Deutsch, N. L. (2013). Setting-level influences on implementation of the Responsive Classroom approach. Prevention Science, 14, 40-51. doi:10.1007/s11121-012-0294-1.

Wanless, S.B., Wallace, T., Cartier, J., Akiva, T., Ferrara, A., Johnson, C. (2014). Helping preservice teachers feel ready to teach: Mindfulness and self-regulation. In K. Schonert-Reichel (Chair), Social and Emotional Learning in Teacher Preparation: Emerging Policy, Research, and Programs. Paper presented at the annual meeting of the American Educational Research Association, Philadelphia.

Wanless, S.B., Briggs, J.O., Pieri, J.W. (2015). Assessing a preschool's readiness to implement using multiple raters and multiple levels. In
Connors, M. (Chair), Opportunities for Change: Maximizing the Impact of Quality Improvement Efforts in Early Care and Education Programs. Paper presented at the biennial meeting of the Society for Research in Child Development, Philadelphia.

Wanless, S. B., Groark, C., \& Hatfield, B. (2015b). Assessing organizational readiness. In J. Durlak, R. Weissburg, \& T. Gullotta (Eds.), Handbook of social emotional learning. New York: Guilford Publications.

Wanless, S. B., Rimm-Kaufman, S. E., Abry, T., Larsen, R. A., \& Patton, C. L. (2015c). Engagement in training as a mechanism to understanding fidelity of implementation of the Responsive Classroom approach. Prevention Science. doi:10.1007/s11121-014-0519-6.

Weissberg, R. P., Durlak, J. A., Domitrovich, C. E., \& Gullotta, T. P. (2015). Social and emotional learning: Past, present, and future. In J. A. Durlak, C. E. Domitrovich, R. P. Weissberg, \& T. P. Gullotta (Eds.), Handbook for social and emotional learning: Research and practice (pp. 3-19). New York: Guilford.

Williford, A. P., Wolcott, C. S., Whittaker, J. V., \& Locasale-Crouch, J. (2015). Program and teacher characteristics predicting the implementation of Banking Time with preschoolers who display disruptive behaviors. Prevention Science. doi:10.1007/s11121-015-05440 .

Wilson, S. J., \& Lipsey, M. W. (2007). School-based interventions for aggressive and disruptive behavior: Update of a meta-analysis. American Journal of Preventive Medicine, 33, S130-S143.

Yoshikawa, H., Leyva, D., Snow, C. E., Treviño, E., Barata, M., Weiland, C., ... Arbour, M. C. (2015). Experimental impacts of a teacher professional development program in Chile on preschool classroom quality and child outcomes. Developmental Psychology, 51, 309322. http://dx.doi.org/10.1037/a0038785. 